\title{
AS APORIAS DA RESPONSABILIDADE: HERESIA E SEGREDO EM \\ DONNER LA MORT, DE DERRIDA, E TEMOR E TREMOR, DE KIERKEGAARD
}

\author{
Maria Elvira Malaquias de Carvalho \\ Doutoranda em Literatura Comparada / UFMG
}

\begin{abstract}
RESUMO
Em Donner la mort, Jacques Derrida estuda a história do conceito de responsabilidade, construindo uma argumentação que torna relevantes as aporias que cercam a apreensão de tal conceito. $O$ texto destaca como o autor empreende a releitura de Temor e Tremor, obra em que Kierkegaard analisa a crise de Abraão no relato bíblico do sacrifício de Isaac. Ao final, são dados os motivos pelos quais Derrida alega que a literatura herda e renega, ao mesmo tempo, a filiação abraâmica a ela atribuída.
\end{abstract}

\section{PALAVRAS-CHAVE}

Derrida, Kierkegaard, responsabilidade, Abraão

Em Donner la mort, livro publicado na França em 1999, ainda não traduzido para o português, o pensador franco-argelino Jacques Derrida examina de modo exaustivo o conceito de responsabilidade enquanto modalidade daquilo que denomina "dar(-se) a morte". O argumento do texto deve ser compreendido como parte essencial do debate em torno da questão do dom, que alcança relevância na obra tardia de Derrida. Como notam os leitores, o pensamento derridiano atravessa disciplinas diferentes, como a filosofia, a literatura, a psicanálise e a religião, e compõe a partir desse panorama epistemológico seu aparato conceitual e discursivo.

$\mathrm{Na}$ primeira parte do livro, denominada "Os segredos da responsabilidade europeia", o autor alude aos Ensaios heréticos sobre a filosofia da história (1975), do filósofo e ensaísta tcheco Jan Patočka (1907-1977). Nesta obra, Patočka desenvolve interessantes formulações sobre a relação entre o mistério do sagrado e a 
responsabilidade, distinguindo a religião da sacralização demoníaca. A religião "supõe o acesso à responsabilidade de um eu livre", ${ }^{1}$ uma vez que se trata de examinar como se deu a passagem do plano do demoníaco para o plano da responsabilidade. O demoníaco é compreendido como a indistinção dos limites que separam o animal, o humano e o divino, e se relaciona com todo o universo do mistério, do exotérico, do segredo e do sagrado. Portanto, a religião, no sentido próprio do termo, só começa quando o mistério orgíaco ou o segredo demoníaco são, quando não totalmente destruídos, pelo menos dominados e subjugados à esfera da responsabilidade.

Estamos diante do conceito de daimon, o qual se associa à gênese do desejo sexual. Assim, o demoníaco define-se, originalmente, pela não responsabilidade, pois “pertence a um espaço onde ainda não há a injunção de responder: onde ainda não se ouve o apelo a responder por si, por seus atos ou pensamentos, a responder pelo outro ou diante do outro". ${ }^{2}$ Segundo Derrida, a gênese da responsabilidade proposta por Patočka "confunde-se com uma genealogia do sujeito que diz 'eu', de sua relação consigo próprio como instância da liberdade, da singularidade e da responsabilidade, e da relação consigo próprio como ser diante do outro". ${ }^{3}$ Derrida sugere também que esta história da sexualidade poderia ser identificada com a história do cristianismo, ou melhor, com o nascimento da Europa no sentido moderno do termo. Logo, a civilização moderna, enquanto civilização europeia, sofreria de uma certa cegueira, por não conhecer sua própria história e não "assumir a responsabilidade, isto é, a memória de sua história como história da responsabilidade". 4

Tornando-se responsável, o homem torna-se histórico. Mas não se trata apenas dessa transformação, pois há também outro segredo que passa a existir no acontecimento cristão do dom sacrifical: é o temor, o pavor, o mysterium tremendum que se apodera do homem "quando este se torna uma pessoa, e a pessoa só pode tornarse o que ela é no momento em que se vê penetrada, em sua singularidade, pelo olhar de Deus". 5 Nota-se aqui a passagem da exterioridade à interioridade, que garante a transição do platonismo ao cristianismo, ainda que seja difícil formalizar um conceito

\footnotetext{
${ }^{1}$ DERRIDA. Donner la mort, p. 15. (tradução nossa)

${ }^{2}$ DERRIDA. Donner la mort, p. 17. (grifo do autor, tradução nossa)

${ }^{3}$ DERRIDA. Donner la mort, p. 17-18. (tradução nossa)

${ }^{4}$ DERRIDA. Donner la mort, p. 18. (grifo do autor, tradução nossa)

${ }^{5}$ DERRIDA. Donner la mort, p. 21. (tradução nossa)
} 
de pessoa, na ótica cristã, no exato momento em que se daria tal advento, como Patočka adverte.

O mysterium tremendum é, na verdade, uma sucessão de mistérios incorporados e recalcados. Para Derrida, “a história do eu responsável edifica-se na herança, no patrimônio de segredos, através de uma série de rupturas e de recalcamentos em cadeia". 6 Desse modo, ainda que Platão tenha rompido com o mistério orgíaco e instaurado "a primeira experiência típica da responsabilidade", 7 o platonismo e o neoplatonismo incorporaram o demoníaco, que lhes foi subordinado, mas jamais suprimido. A partir dessa história de segredos, que constitui o cerne da história da responsabilidade que Derrida estuda, o texto coloca em relevo a questão do dom e da morte dada, a qual significa uma espécie de aliança da responsabilidade e da fé. O que quer dizer dar a morte? Como é possível morrer sacrificando-se pelo outro, dando sua vida ao dar-se a morte? O que é morrer pelo outro? Qual é a relação entre o dar-se a morte e o sacrifício?

Derrida refere-se ao Fédon, de Platão, e à instauração da filosofia como uma disciplina cujo objetivo é o exercício da morte. Esse primeiro despertar da responsabilidade corresponde ao nascimento da filosofia. A doutrina platônica da imortalidade da alma seria o resultado de uma confrontação do orgíaco com a responsabilidade, mais especificamente, de um triunfo da responsabilidade sobre o mistério orgíaco. Refere-se também à guerra como experiência da morte dada, sobretudo à ideia de que a Segunda Guerra Mundial possibilitou certa identificação com o inimigo, ou o desaparecimento da figura do inimigo (Carl Schmitt). Mas a experiência da morte está ligada, sobretudo, à singularidade de um eu insubstituível, de tal modo que "a morte é justamente aquilo que ninguém pode sofrer ou afrontar em meu lugar". 8 De acordo com Heidegger, mencionado no livro, cada ser deve tomar para si o morrer. Cada um deve assumir a responsabilidade de sua própria morte. (Das Sterben muss jedes Dasein jeweilig selbst auf sich nehmen.) A morte suspende toda experiência do dar-tomar, porque não se toma nem se dá a morte.

Derrida não cansa de insistir que a genealogia da responsabilidade é ambígua. Devemos ficar atentos a uma mitologia da liberdade responsável e a uma afirmação

\footnotetext{
${ }^{6}$ DERRIDA. Donner la mort, p. 22. (grifo do autor, tradução nossa)

${ }^{7}$ DERRIDA. Donner la mort, p. 22. (tradução nossa)

${ }^{8}$ DERRIDA. Donner la mort, p. 64. (tradução nossa)
} 
triunfante do eu livre. Há aqui toda uma operação interpretativa ligando a responsabilidade à heresia. É assim que Derrida chega à obra do filósofo e teólogo dinamarquês Søren Kierkegaard. A heresia é o afastamento ou o desvio de uma doutrina oficial, de uma doxa, de um saber instituído publicamente, ou da lei de uma determinada comunidade. Temor e Tremor, publicado em 1843 e cujo prefácio é assinado sob o pseudônimo de Johannes de Silentio, examina o caminho solitário que Abraão percorre, ao sofrer uma provação de Deus para imolar seu único e amado filho, no episódio bíblico do sacrifício de Isaac. Kierkegaard procura compreender a crise de Abraão, o Patriarca da Fé, e aponta os contrastes dialéticos vividos pelo eleito de Deus. Conclui-se que a fé é um "paradoxo capaz de transformar um crime em ato santo e agradável a Deus, paradoxo que devolve a Abraão o seu filho (...) e que não pode ser reduzido a qualquer raciocínio, pois a fé principia exatamente onde termina a razão".9

Para Kierkegaard, a fé não é um simples impulso de ordem estética, porém um paradoxo da vida. A fé engendra um movimento que deve realizar-se em razão do absurdo, sem que se perca de vista o mundo finito, pois a preservação deste último deve ser o objetivo final do crente. A crise religiosa de Abraão representa uma suspensão teleológica da moralidade, porque o Indivíduo se põe acima do geral, no momento em que a fé entra em choque com a generalidade da ética. Kierkegaard lida com as categorias hegelianas das Äußere (o exterior, a manifestação) e das Innere (o íntimo, o secreto). O Indivíduo é o ser oculto, cuja missão moral é "livrar-se do secreto para darse a conhecer no geral". Porém, toda vez "que deseja ficar escondido comete um pecado e entra em crise da qual apenas pode sair pela manifestação". ${ }^{10}$

Abraão constitui o herói da fé, ou o "cavaleiro da resignação infinita", como é denominado pelo autor dinamarquês. O herói da fé possui características distintas daquelas apresentadas pelos heróis trágicos, como Agamemnon, por exemplo. Abraão é diferente do herói clássico porque lhe falta a instância intermediária: não age para salvar um povo, para defender a ideia de Estado ou tampouco para apaziguar os deuses furiosos. Abraão age por uma virtude inteiramente pessoal, por meio da qual ingressa em um estado em que "não pode fazer-se entender por quem quer seja". ${ }^{11}$ Esta recusa à mediação da palavra e à manifestação do sofrimento proporciona ao leitor que se

\footnotetext{
${ }^{9}$ KIERKEGAARD. Temor e Tremor, p. 47.

${ }^{10}$ KIERKEGAARD. Temor e Tremor, p. 75.

${ }^{11}$ KIERKEGAARD. Temor e Tremor, p. 65.
} 
aproxima da história de Abraão um sentimento de horror religiosus, porque não é possível chorar por ele. O herói trágico, em contrapartida, tem necessidade de lágrimas e reclama-as, dividindo com os outros sua dor. Kierkegaard descreve com precisão a diferença do conflito entre o herói trágico e o herói da fé. O primeiro renuncia ao desejo para dar cumprimento ao dever. Agamemnon não fugiu ao seu dever paterno, porque "a obrigação moral está inteiramente presente em si mesma pelo fato de que a pode transmudar em desejo". ${ }^{12}$ Para o cavaleiro da fé, o desejo e o dever são inteiramente semelhantes; no entanto, ele se vê na obrigação de renunciar tanto a um como a outro.

Em todo o episódio bíblico do sacrifício de Isaac, o silêncio do Patriarca incomoda não só a Kierkegaard mas também a Derrida, que empreende a releitura de Temor e Tremor em seu Donner la mort. Abraão transgride a ordem da ética, ao guardar em segredo seu ato, subtraindo-se de seu dever para com sua família, seus próximos e sua comunidade. Não falando, Abraão assume a responsabilidade de "estar sempre sozinho e recolhido em sua própria singularidade no momento da decisão". ${ }^{13}$ Tal fato também constitui um escândalo para a estética, uma vez que esta última "admite que a mim mesmo me sacrifique, porém não que imole um outro por minha causa". ${ }^{14}$ Abraão não pode falar e tampouco obter apaziguamento pela palavra, não pode usar qualquer linguagem humana, de maneira que "sua linguagem é divina, fala as línguas". 15

Isaac e seu pai escalaram o monte Morija em silêncio. Em um determinado momento, entretanto, a criança pergunta ao pai onde estava o cordeiro para o sacrifício. A resposta de Abraão é intrigante: "Meu filho, Deus cuidará ele mesmo do cordeiro para o holocausto." Esta única frase que restou de toda a narrativa "assume a forma de ironia, pois é sempre ela que se usa para expressar alguma coisa, sem, contudo, dizer seja o que for". ${ }^{16}$ O pai não mente para o filho, mas, de certo modo, dissimula a verdade. Segundo Kierkegaard, Abraão não diz uma mentira, "porém igualmente não diz outra coisa, pois que fala uma língua estranha". Também fascinado com a resposta do pai ao filho, Derrida indagará que tipo de responsabilidade é esta que "não consiste

\footnotetext{
${ }^{12}$ KIERKEGAARD. Temor e Tremor, p. 72.

${ }^{13}$ DERRIDA. Donner la mort, p. 87. (tradução nossa)

${ }^{14}$ KIERKEGAARD. Temor e Tremor, p. 105.

${ }^{15}$ KIERKEGAARD. Temor e Tremor, p. 107. (grifo do autor)

${ }^{16}$ KIERKEGAARD. Temor e Tremor, p. 111.
} 
nem em responder nem em não responder”. Como é possível ser responsável por aquilo que dizemos "em uma linguagem ininteligível, na língua do outro?"17

A narrativa do sacrifício de Isaac ilustraria o paradoxo que habita o conceito de dever e de responsabilidade absoluta. Tomada como exemplo para discutir as aporias do conceito de responsabilidade, esta herética narrativa pertence ao tesouro comum das três religiões chamadas abraâmicas: o judaísmo, o cristianismo e o islamismo. "O exercício da responsabilidade não parece deixar outra escolha, por mais desconfortável que ela seja, que o paradoxo da heresia e do segredo", ${ }^{18}$ afirma Derrida, que enfatiza a monstruosidade e o caráter inaudito dessa história:

Um pai pronto a dar a morte a seu filho bem amado, a seu amor insubstituível, e tudo isso porque o Outro, o grande Outro lhe pede e ordena, sem lhe dar a menor razão; um pai infanticida que esconde a seu filho e aos seus o que vai fazer e sem saber o motivo. Que crime abominável, que mistério horrível (tremendum) contra o amor, a humanidade, a família e a moral! ${ }^{19}$

A partir dessa origem comum das religiões ditas do Livro, Derrida finaliza Donner la mort apontando a possibilidade de emergência da literatura, aliada ao tema do segredo, isto é, inscrevendo "a questão do segredo como segredo da literatura sob o signo aparentemente improvável de uma origem abraâmica" ${ }^{20}$ A literatura, no sentido que esta palavra adquire no Ocidente e para o Ocidente, herda e renega tal filiação abraâmica. Como alega Derrida, essa instituição moderna, que recebe legitimamente o nome de literatura, "dessacraliza e seculariza as Escrituras, a Escritura santa ou sagrada, repetindo, desnudando e oferecendo ao mundo o sacrifício de Isaac". ${ }^{21}$ São dados alguns atributos da literatura que supostamente adviriam desta influência abraâmica, quais sejam: o direito de tudo dizer e de tudo esconder; a exoneração do signatário da obra quanto à responsabilidade do sentido e do referente, diante da lei cívica ou política; a suspensão de uma correspondência direta entre o mundo e os efeitos de segredo cifrados no acontecimento literário; o direito literário à ficção supõe uma história que institui uma autorização para a realização de atos de linguagem, dado que o estatuto do autor admite que este seja irresponsável e hiper-responsável ao mesmo tempo; a emergência

\footnotetext{
${ }^{17}$ DERRIDA. Donner la mort, p. 105. (tradução nossa)

${ }^{18}$ DERRIDA. Donner la mort, p. 47. (tradução nossa)

${ }^{19}$ DERRIDA. Donner la mort, p. 97. (tradução nossa)

${ }^{20}$ DERRIDA. Donner la mort, p. 177. (tradução nossa)

${ }^{21}$ DERRIDA. Donner la mort, p. 203. (tradução nossa)
} 
do direito antes mencionado implica aceitar que a função literária só acontece a partir de significados e contextos validados fora do âmbito literário.

Jacques Derrida não faz qualquer alusão ao clássico Mimesis, de Erich Auerbach. Como se sabe, o legado que o filólogo alemão deixou para os estudos literários consiste na descrição pormenorizada de duas grandes tradições estilísticas que se confrontaram na cultura ocidental. Os dois estilos, oriundos de Homero e do Velho Testamento, exerceram uma influência constitutiva sobre a representação europeia da realidade e, progressivamente, foram se misturando até a dissolução das hierarquias de gêneros literários. Derrida não se envereda pelo tipo de argumentação que Auerbach desenvolve, mesmo quando este se refere ao modo particular de ver e representar oriundo da noção judaica de Deus. Ao comentar o relato do sacrifício de Isaac, principalmente o esboço de diálogo entre o pai e o filho, Erich Auerbach pontua que "nada dos interlocutores é manifesto, exceto as palavras, breves, abruptas, que se chocam duramente, sem preparação alguma; quando muito a representação de um gesto total de entrega; tudo o mais fica no escuro.”22 Tal observação não é válida para os poemas homéricos, que nada ocultam, pois o objetivo do estilo homérico seria "representar os fenômenos acabadamente, palpáveis e visíveis em todas as suas partes, claramente definidos em suas relações espaciais e temporais". ${ }^{23}$

Em suma, Derrida parece querer extrair de um mito um poderoso e sofisticado aparato epistemológico que atestaria a nossa incapacidade de formalizar um conceito estável de responsabilidade e de dever, insistindo sobre as fontes irracionais, inconscientes ou religiosas que, desde sempre, atravessaram estas duas noções. Isto leva a dizer que há algo de irremediavelmente demoníaco no interior de todo ato supostamente responsável, e que, em vão, logramos destruir este daimon incorporado na própria gênese do devir-responsável do homem. "O sacrifício de Isaac continua todos os dias", ${ }^{24}$ aponta o autor, transportando a narrativa do Gênesis para o domínio prosaico de nossas vidas. Reler hoje Donner la mort é perceber como Derrida enfrentou, com sua obra repleta de aporias e enigmas, o agudo ressurgimento dos questionamentos acerca da responsabilidade do homem sobre seus atos e pensamentos.

\footnotetext{
${ }^{22}$ AUERBACH. Mimesis: a representação da realidade na literatura européia, p. 6.

${ }^{23}$ AUERBACH. Mimesis: a representação da realidade na literatura européia, p. 4.

${ }^{24}$ DERRIDA. Donner la mort, p. 100. (tradução nossa)
} 


\begin{abstract}
In The Gift of Death, Jacques Derrida studies the history of the concept of responsibility, building an argument that makes the aporias surrounding the concept relevant. The text highlights the author's rereading of Fear and Trembling, in which Kierkegaard analyzes Abraham's crisis in the biblical narrative of the sacrifice of Isaac. At the end, Derrida presents his reasons for affirming that literature inherits and disowns, at the same time, its Abrahamic filiation.
\end{abstract}

KEYWORDS

Derrida, Kierkegaard, responsibility, Abraham

\title{
REFERÊNCIAS
}

AUERBACH, Erich. Mimesis: a representação da realidade na literatura européia. 5. ed. Vários tradutores. São Paulo: Perspectiva, 2007. (Coleção Estudos; 2 / Dirigida por J. Guinsburg.)

DERRIDA, Jacques. Donner la mort. Paris: Galilée, 1999.

KIERKEGAARD, Søren. Temor e Tremor. Trad. e prefácio de Torrieri Guimarães. São Paulo: Hemus, 2008. 